\title{
APRESENTAÇÃO DO DOSSIÊ: "ESTUDOS SOBRE O ENSINO SECUNDÁRIO NO CONE SUL NOS ANOS 1950 E 1960"
}

DOI: http://dx.doi.org/10.1590/2236-3459/84515

\author{
Norberto Dallabrida' \\ "Universidade do Estado de Santa Catarina (Udesc), Florianópolis/SC, Brasil \\ Myriam Southwell" \\ "Conicet/Universidad Nacional de La Plata (UNLP), Buenos Aires, Argentina
}

$\cos 80$

atual escolarização média apresenta impasses que envolvem a sua
democratização quantitativa e a sua atualização pedagógica. Os
questionamentos sociais sobre este nível de ensino têm forçado governos a dar respostas consequentes e instigado educadores e cientistas sociais a produzirem respostas convincentes. Historiadores da educação têm envidado esforços no sentido de compreender a questão a partir de leituras temporais de longa e de média duração. Devido à colonização ibérica, nos países da América Latina o ensino secundário foi plasmado pela Igreja Católica por meio de uma rede articulada de colégios confessionais, contribuindo para a permanência do tradicionalismo pedagógico. A presença católica mais marcante no ensino secundário em países latino-americanos deu-se a partir do final do século XIX por meio da atuação de congregações religiosas europeias, em boa medida expulsas de países que laicizavam o Estado e o seu sistema público de ensino, como a França e a Alemanha. No ensino secundário foram sobremaneira as congregações formadas por padres que criaram e gestionaram colégios dirigidos às elites masculinas.

No entanto, após a Segunda Guerra Mundial, a ação da Unesco e a intensificação da globalização estimularam a realização de experiências renovadoras no ensino secundário em países latino-americanos (XAVIER, 1999). As ideias e modelos pedagógicos que passaram a circular e a ser usados foram, especialmente, aqueles produzidos nos EUA, como o plano Morrison, e na França, tendo como referências as classes nouvelles, vinculadas ao Centre International d’Études Pedagogiques (Ciep), localizado em Sévres, e a Pedagogia Personalizada e Comunitária, elaborada pelo padre jesuita francês Pierre 
Faure. Enquanto as classes nouveles tiveram recepção nos sistemas públicos de ensino, a pedagogía escolanovista católica do padre Faure disseminou-se mais, mas não exclusivamente, nos colégios católicos, particularmente no México, na Colômbia e no Brasil. Não se trata da renovação do ensino secundário em larga escala, mas da realização de experiências vanguardistas pontuais, que apontaram um caminho alternativo para o ensino secundário homogeneizado pelo timbre autoritário dos anos 1930 e 1940.

No clima da guerra fria, impulsionado pelo pan-americanismo produzido pela Organização dos Estados Americanos (OEA) e chancelado pelos EUA, foram realizados eventos para debater a educação escolar no continente americano. Assim, em janeiro de 1955, ocorreu, em Santiago, o Seminário Interamericano de Educação Secundária, promovido pela OEA e pelo governo do Chile. Tratou-se de um evento singular em que os representantes dos países americanos apresentaram uma radiografia do formato do ensino secundário em seus respectivos sistemas nacionais de ensino e promoveram uma importante troca de experiências escolares (ABREU, 1955). Outro exemplo foi a realização do Congresso Pan-Americano de Educação Física, também ocorrido na capital do Chile, no ano seguinte, que contou com a participação de Germano Bayer, professor do Colégio Estadual do Paraná, e Gildásio Amado, titular da Diretoria do Ensino Secundário do Ministério da Educação e Cultura do Brasil. Segundo Chaves Júnior (2016), esses dois educadores visitaram o Liceo Experimental Manuel Salas, localizado em Santiago, que realizava um ensaio educacional renovador no ensino secundário. Há, portanto, indícios de certa circulação e apropriação de experiências educativas no ensino secundário entre os países do continente americano, certamente mais frequentes entre os de língua espanhola.

A pequena onda de renovação do ensino secundário nos países da América Latina, proporcionado pelo clima democrático e de abertura internacional no campo educacional, foi coibida pelas ditaduras militares dos anos 1960 e 1970 no subcontinente latinoamericano. Refletindo sobre o autoritarismo militar e escolarização no Uruguai, Southwell (2010, p. 14) assevera que "el régimen [militar] entendió que la escuela era responsable de desborde de la cultura política y desde esa convicción operó para generar mayores formas de control político sobre la cultura escolar y el trabajo pedagógico". Mutatis mutandis, essa constatação pode ser estendida às ditaduras latino-americanas que procuraram intervir nos seus sistemas de ensino, inicialmente no nível superior porque as universidades eram um dos principais focos de resistência democrática, mas também nos ensinos primário e secundário. As ditaduras abortaram experiências educativas e ideias pedagógicas ricas e criativas, em boa medida inspiradas em modelos pedagógicos estrangeiros, mas também em propostas pedagógicas elaboradas e usadas na América Latina como a de Paulo Freire.

Nesta direção, o presente dossiê tem como intuito realizar uma leitura histórica e comparada da renovação do ensino secundário, nas décadas de 1950 e 1960, em países do Cone Sul, de sorte que os autores dos textos analisam a escolarização de seus países. No artigo "Formato, pedagogias y planeamiento para la secundaria en Argentina. Notas sobresalientes del siglo XX, Myriam Southwell apresenta uma trajetória panorâmica do ensino secundário na Argentina durante o novecentos. Tal panorama parte da criação do modelo de colégio de ensino secundário direcionado às elites burguesas no final do século XIX, mas sobretudo lança luz sobre as renovações que se colocaram no ensino secundário argentino a partir da expansão, modernização e ressignificação escolanovista dessa etapa da escolarização. Em "Las asambleas de profesores en la consolidación del consejo de 
enseñanza secundaria en Uruguay (1949-1961)", Lucas D'Avenia analisa as chamadas assembleias de professores secundaristas no Uruguay, procurando compreender a emergência dessas assembleias no momento do início da massificação da matrícula do ensino secundário e, especialmente, a circulação de ideias pedagógicas e espaço de empoderamento docente.

Os artigos de autores brasileiros colocam o foco sobre as chamadas classes secundárias experimentais, que se constituíram na principal experiência pedagógica no ensino secundário brasileiro nas décadas de 1950 e 1960. No artigo "Luis Contier como catalisador de redes: classes experimentais e renovação do ensino secundário em São Paulo nas décadas de 1950 e 1960", Daniel Ferraz Chiozzini e Letícia Vieira refletem sobre a contribuição do educador-intelectual Luís Contier na implantação da primeira experiência renovadoras no ensino secundário a partir das classes nouvelles, bem como na instituição das classes secundárias experimentais a partir do final dos anos 1950. Em "A inspiração nos trabalhos dos grandes centros de estudos pedagógicos: considerações sobre as classes integrais do Colégio Estadual do Paraná (1960-1967)", Sérgio Roberto Chaves Júnior analisa o ensaio educacional das classes secundárias experimentais, na década de 1960, na principal escola pública do Paraná, que tinha conexões com o Colégio Nova Friburgo, referência no uso do método de ensino por unidades didáticas inspirado no plano Morrison. No artigo "Circuito e usos de modelos pedagógicos renovadores no ensino secundário brasileiro na década de 1950", Norberto Dallabrida busca compreender os processos de circulação e de apropriação das classes nouvelles e da Pedagogia Personalizada e Comunitária no Brasil.

Os cincos artigos que compõem o presente dossiê, portanto, proporcionam estudos sobre o ensino secundário no Cone Sul em perspectiva histórica e comparada, apostando na intensificação da troca de reflexões educacionais e pedagógicas na América Latina. Esse trabalho pretérito tem 0 fito de contribuir para subsidiar as reformas o ensino secundário/médio em curso, de modo que este nível de escolarização seja pedagogicamente consistente e socialmente justo.

\section{Referências}

ABREU, Jayme. A Educação Secundária no Brasil. Rio de Janeiro: MEC/Inep, 1955. (Publicações da Cileme, 9).

CHAVES JÚNIOR, Sérgio Roberto. As inovações pedagógicas do ensino secundário brasileiro nos anos 1950/1960: apontamentos sobre as classes integrais do Colégio Estadual do Paraná. Cadernos de História da Educação, Uberlândia, v. 15, n. 2, p. 520539, maio/ago. 2016.

SOUTHWELL, Myriam. Prólogo. In: ROMANO, Antonio. De la reforma al proceso: una historia de la Enseñanza Secundaria (1955-1977). Montevideo: Ediciones Trilce, 2010. p. 11-14.

XAVIER, Libânia Nacif. O Brasil como Laboratório: Educação e Ciências Sociais no Projeto dos Centros Brasileiros de Pesquisas Educacionais CBPE/Inep/MEC (1950-1960). Bragança Paulista: Edusf, 1999. 
NORBERTO DALLABRIDA é Doutor em História pela Universidade de São Paulo (USP) e professor do Programa de Pós-Graduação em Educação da Universidade do Estado de Santa Catarina (Udesc). Pesquisador do CNPq. Com Rosa Fátima de Souza, organizador da coletânea "Entre o ginásio de elite e o colégio popular: estudos sobre o ensino secundário no Brasil (1931-1961)".

Endereço: Rua Henrique Bruggemann, 40 - ap. 304, Centro, 88015-650, Florianópolis/SC, Brasil.

E-mail: norbertodallabrida@gmail.com

MYRIAM SOUTHWELL es investigadora independiente Conicet/Universidad Nacional de La Plata, directora del Doctorado en Ciencias de la Educación de la Universidad Nacional de La Plata. Fue presidente de la Sociedad Argentina de Historia de la Educación entre 2008 y 2012 y desde 2016 es integrante del Comité Ejecutivo de International Standard Conference on History of Education (Ische). Autora de numerosos trabajos en temas de historia y política de la educación entre los cuales se destacan Ideas en la Educación Latinoamericana. Un balance historiográfico (junto con Nicolás Arata), Unipe, 2014; Reflexiones sobre el Congreso Pedagógico Internacional de 1882 (junto con Jorge Bralich), Trilce, 2014; Schooling and Governance: Pedagogical Knowledge and Bureaucratic Expertise in the Genesis of the Argentine Educational System, Paedagogica Historica, v. XLIX, 2013; La educación y lo justo. Ensayos acerca de las medidas de lo posible, Unipe, 2013; Entre Generaciones. Exploraciones sobre educación, cultura e instituciones, Homo Sapiens, 2012.

Dirección postal: Calle 135, nro. 145, 1896, La Plata, Argentina.

E-mail: islaesmeralda@gmail.com

Recebido em 04 de julho de 2018.

Aceito em 04 de julho de 2018. 